\title{
The Human Microbiome and I-Cubed: A Modern Medical Paradigm
}

\section{David S. Younger}

Department of Neurology, Division of Neuro-Epidemiology, New York University School of Medicine, and the College of Global Public Health, New York University, New York, NY, USA

Email: youngd01@nyu.edu

How to cite this paper: Younger, D.S. (2016) The Human Microbiome and ICubed: A Modern Medical Paradigm. World Journal of Neuroscience, 6, 260-286. http://dx.doi.org/10.4236/wjns.2016.64031

Received: September 15, 2016

Accepted: October 24, 2016

Published: October 27, 2016

Copyright $\odot 2016$ by author and Scientific Research Publishing Inc. This work is licensed under the Creative Commons Attribution International License (CC BY 4.0).

http://creativecommons.org/licenses/by/4.0/ (c) (i) Open Access

\begin{abstract}
Background: Over the past decade, there has been recognition of the importance of the human microbiome. Beyond improved microbial cataloguing through highthroughput genetic sequencing, we have learned that human beings are superorganisms integrating the identity, function and immunity of resident bacterial, while prepared throughout own innate and adaptive immune systems, to deal with invading organisms. Hypothesis: In keeping with the dynamic relation of infection, immunity and inflammation contained in I-Cubed, illness arises when protective immunity becomes the source of autoimmunity, conditioned by environmental and genetic factors. Results: This paradigm explains the etiopathogenesis of diverse medical (type 1 diabetes, spondyloarthropathy), neurologic (Lyme neuroborreliosis), and neuropsychiatric disorders (PANDAS, and autism spectrum disorders). Conclusion: Successful treatments employing immune-modulatory therapy may be employed. Public health officials will be called upon to guide the public's understanding and mitigate the risk of disorders that result from the interplay of the human microbiome and I-Cubed.
\end{abstract}

\section{Keywords}

I-Cubed (Infection, Immunity, Inflammation), Microbiome, Neuroepidemiology

\section{Introduction}

The human microbiome, defined as the collection of microorganisms that reside within our body, has coevolved over the history of mankind, and has been overlooked as determinants of health and disease. Given the appearance of new microbial agents and the everyday occurrence of unexplained lethal neurological syndromes of suspected infec- 
tious etiology, scientists have begun to identify a plethora of microbial agents in our body and in the human genome. The true capability of such microbes residing in our body to cause human disease has become the focus of medical science. Post-infectious autoimmune illness is increasingly recognized due to resident and invasive microbial agents that have the capacity to trigger our immune system, turning it on and off at will. With differences in resident microbial niches, imperfect host defenses, and susceptibility to epidemic and endemic diseases in the environment, there are ever increasing opportunities for bacterial, virus, and parasitic exposures.

The triumvirate rate of infection, immunity and inflammation, abbreviated as I-Cubed $\left(\mathrm{I}^{3}\right)$, posits that complex self-sustaining responses from infectious insults to the nascent immune system, whether by contagious or innate sources endemic to ones' microbiome, may explain the etiopathogenesis of diverse medical, neurologic and neuropsychiatric disorders, notably type 1 diabetes (T1D), spondyloarthropathy (SpA), Lyme neuroborreliosis (LNB), pediatric autoimmune neuropsychiatric disorder associated with streptococcal infection (PANDAS), and autismspectrum disorders (ASD). Underlying genetic vulnerability, pre- and post-natal factors and individual differences in exposure timing and host immune responses may further explain differences in eventual outcome. Innovative therapeutic strategies involving immune modulation may be effective in some affected patients.

The public health community needs to be aware of the advances in the human microbiome and its interplay with autoimmunity in order to effectively provide surveillance and communication to different potential groups of users to whom they refer, and to mitigate the risk to society [1].

\section{Human Microbiome}

For an appreciation of the human microbiome, imagine the excitement of a scientist at a medical conference claiming to have discovered a new human organ which likes the immune system, contains collections of cells and a 100-times more genes than the host. Not only is it tailored to the individual host, but it is modifiable by stress, diet, medications, exercise, and antibiotics. When lost, nearly all aspects of the host's normal physiological function are altered. Although it has been known for some time that the human body is inhabited by resident flora in a factor greater than 10:1, Most researchers have focused instead on a minority of disease-causing or "pathogenic" organisms with far fewer examining the benefits of the resident bacterial flora.

The concept of the human microbiome or microbiota originated with the Rockefeller University scientist Joshua Lederberg [2] as an ecological community of commensal, symbiotic, and pathogenic microorganisms sharing our body space. It is estimated that $20 \%$ to $60 \%$ of the human-associated microbiome, depending on body site, is still resistant to conventional culture techniques making it difficult to accurately estimate its true diversity. More recently, the human microbiome has been studied in different biological states using gene sequencing techniques. Scientists have used molecular tools to extract and compare bits of a particular kind of ribonucleic acid (RNA) the products of 
deoxyribonucleic acid (DNA) transcription and translation, to determine if previously known or new microbes were present in a particular human tissues such as blood. This technique which is widely used as a biomarker for microbial disease uses a particular kind of RNA known as $16 \mathrm{~S}$ ribosomal RNA (rRNA). Since the genes for ribosomal RNA have changed little over millions of years as organisms have evolved, slight changes in their composition provide valuable clues to the very nature of microbial organisms located in the human body. The 16S rRNA gene is very short, just 1542 nucleotide bases making it quickly and cheaply copied, sequenced and then compared to libraries of stored 16S rRNA genes from numerous known bacteria. The ones that match up perfectly are microbes that have been previously identified while others that show differences may be previously unknown microbes. Such studies of gastrointestinal microbes at the 16S rRNA gene level have revealed significant diversity in the flora of individuals. We are presently at a public health crossroads, in a position to make gigantic gains in our knowledge to better understand how microbes impact on human health, transitioning from description to causality and microbial engineering. Underscoring this, two papers published simultaneously in the journals Science [3] and Nature [4] called for the establishment of a Unified [domestic] Microbiome Initiative and International Microbiome Initiative.

With more than $90 \%$ of cells in the human micobiome understood to be bacterial, viral, parasitic, fungal or otherwise non-human in nature, and human metabolism and immunity attributed to the molecular genetic contribution of microbial and human interaction, human beings are being referred to as superorganisms. In the last decade the United States (U.S.) Human Microbiome Project and European MetaHit, two largescale genomic projects, along with several private efforts, have investigated the microbiota in a variety of human body niches using new molecular genetic tools. While many sites such as the skin, oral and nasal cavities, and vagina are all relatively easy to access, the majority of research in this area has focused on the gastrointestinal tract, in particular the colon. A newly recognized axis of communication between the gut and brain has led to the recognition of a mind-gut connection attempts to explain the spectrum of functional symptoms from anxiety and depression to irritable bowel syndrome (IBS). With five phyla representing the majority of bacteria that comprise the gut microbiota, there are about 160 species in the large intestine alone of any individual, and very few of these are shared between individuals. The functions contributed by these species appear to be found in everybody's gastrointestinal tract, an observation that suggests that microbial function is more important than the identity of the species providing it. Our understanding of human microbial biology first derived from pure cultures and genomic sequencing, has been limited by sampling bias toward four bacterial phyla, Proteobacteria, Firmicutes, Actinobacteria and Bacteriodes, out of the 35 bacterial and 18 known archael phylum-level lineages. With roughly two-thirds of published microbiological research dedicated to only eight bacterial genera, all of which grow well on agar culture plates, it is unlikely that they are representative of the 5000 or more species known to us. 


\section{I-Cubed: Infection Activates Immunity}

Immunity was historically understood for its purported effects due to active immunization. The first type was the effect of immunization that resulted in definable changes in the cell-free bodily fluid or serum or humor while another was the observed protective effect associated with multiplication of specific cells. Two primordial types of immune cells are now recognized, one lineage termed B-cells that mature in the bone marrow and further differentiate into plasma cells and memory cells. Mature plasma cells are capable of producing antibodies capable of latching onto their target in a lock-and-key specific fashion when their surface antibody receptors recognize other cells displaying foreign antigens. Other B-cells mature into memory B-cells that circulate in the blood stream. The other cell lineage, termed T-cells, also derived in the bone marrow, instead passes though the thymus gland where they achieve their final maturation, and is thought to be most protective in recognizing virus-infected cells. These cells participate in the defense against intracellular bacterial, fungi and protozoan infections; cancers and transplant rejection. Other aspects of enhanced cellular immunity include the secretion of cell-signaling molecules termed cytokines that promote cell-to-cell communication in immune responses and stimulate the movement of cells towards sites of inflammation and infection.

Not surprisingly, major understandings of the pathophysiology of autoimmune diseases have been achieved through an appreciation of infectious triggers of the humoral and cell-mediated immune system. When first identified as the causative agent of the neurological disorder, Whipple disease almost 25 years ago by Relman and coworkers [5], it was unclear whether the uncultured bacillus Tropheryma (T.) whippelii was a rare member of the normal human microbial flora and whether it might be associated with other human diseases. Whipple disease causes a systemic infection which unrecognized and therefore untreated, involves the gastrointestinal tract, heart, and brain. According to phylogenetic analysis the isolated bacterium was a gram-positive Actinomycetes not closely related to any known genus. A molecular genetic approach amplifying a 16SrRNA sequence directly from tissues of five unrelated patients determined its nucleotide sequence. A decade later, the same authors [6] performed ultrastructural studies of intestinal biopsy specimens from affected patients. These studies showed the location of T. whippelii rRNA to be most prevalent near the tips of the intestinal villi in the lamina propia just basal to the epithelial cells, located between cells and not intracellular indicating that the bacillus grew outside cells and that it was not an obligate intracellular pathogen. Such studies ushered in a generation of molecular genetic technology used today in the study of resident human microbes.

Relman [7] observed that molecular, cultivation-independent methods revealed that the distribution and diversity of microorganisms in the world was far greater than previously appreciated. One particular molecular genetic technique compared humantissue derived DNA sequences with those of known pathogenic and commensal bacterial, viral, fungal and protozoan genomes in established expressed-sequence tag libraries. However, inefficient and cost-ineffective for screening large numbers of specimens 
in most laboratories has revealed surprising findings of nonhuman genetic sequences that appeared to be an inherent feature of the human genome. For example, it appears that all humans have human endogenous retrovirus sequences as an integral part of their genome [8]. At some time during the course of human evolution, exogenous progenitors of the human endogenous retrovirus inserted itself into the human germ-line reproductive cells where they were replicated along with the host cellular genes. However intact disease-producing retroviruses differ in the presence of at least one additional coding region, the env gene that encodes viral membrane proteins that mediate the budding of virus particles to the cellular receptors enabling virus entry as the first step in the pathway to a new replication cycle and disease pathogenicity.

Hajjeh and coworkers [9] observed that unexplained deaths and critical illness possibly due to infectious causes in previously healthy persons occurred at an incidence rate of 0.5 per 100,000 per year from 1995 to 1998 among 7.7 million persons in four U.S. Emergency Infectious Programs. However, only two-thirds of which were diagnosed by reference serological tests and the remaining one-third by PCR based methods. These findings suggested the need for molecular genetic surveillance approaches to detect present and emerging infectious diseases. New molecular biological techniques have led to the identification of several previously unculturable infectious agents such as non-A and non-B hepatitis, and hantavirus [10]. Real-time PCR methods with primers and a probe targeting conserved regions of the bacterial 16S rRNA revealed rRNA in blood specimens from healthy individuals raising the possibility that there were normal populations of bacterial DNA sequences in the blood compartments previously been considered sterile at least most of the time. While persistent infection is a potential source of nonhuman sequences in normally sterile human anatomic sites, not all bona fide pathogens have been associated with pathology.

The immunological mechanisms and interactions between resident microbial agents and the human host have been studied at various body sites. The interaction between resident oral bacteria and human gingival epithelial cells in culture demonstrate their potential for virulence. The microbial agents frequently associated with periodontal diseases, include Bacteroides forsythus, Campylobacter curvus, Eikenella corrodens, Fusobacterium (F.) nucleatum, Porphyromonas gingivalis, and Prevotella intermedia. The effects of these bacteria on the production of interleukin (IL)-8, a proinflammatory chemokine, were also measured. F. nucleatum adheres to, and invades human gingival epithelial cells accompanied by high levels of IL-8 secretion from the epithelial cells [11]. By electron microscopy, this invasion occurs via a zipping mechanism that requires the active involvement of actins, microtubules, signal transduction, protein synthesis, and energy metabolism of the human gingival epithelial cells, as well as protein synthesis by $F$. nucleatum.

Other investigators [12] noted a heightened risk of inflammatory bowel disease (IBD), SpA, and colorectal cancer (CRC) between diffusely adherent Eschericia coli and areas of dysplastic mucosa of the colon that made it easier for the bacterial pathogens to gain direct contact with the mucosal surface, a location that is relatively sterile in the 
normal colon. This allowed interaction between bacterial components and intrinsic Tcell receptors of the human mucosa with subsequent downstream protein signaling as the mechanism for early oncogenesis illustrating yet another molecular genetic property of the resident bacteria in their putative role in genotoxicity and human disease. If epithelial-associated bacteria play a causative role in IBD and colorectal cancer, then dietary consumption of soluble plant fibers that prevent mucosal recruitment of bacteriamay be protective against both conditions.

Post-infectious autoimmunity is a recognized phenomenon with several theories to explain its occurrence including molecular mimicry, bystander activation, and viral persistence [13]. Alone or in combination, these mechanisms have been used to account for the immunopathology observed at the site of infection and in distant areas of the body. Molecular mimicry occurs when there are shared immunologic identities or epitopes between the microbe and host. One well recognized example is rheumatic fever, a systemic autoimmune disease that occurs after GABHS infection wherein affected patients develop and manifest circulating antibodies to the bacterial organism reactive to the heart, joint, and brain leading to the cardinal manifestations of rheumatic fever. Pediatric autoimmune neuropsychiatric disease associated with GABHS infection is another example of bacterial-based molecular mimicry. There is a reciprocal dynamic between the central nervous system (CNS) and immune system, conditioned by the microbiome that regulates a cross-talk [14] which is easily perturbed by pre- and post-natal exposure to pathogens and genetic vulnerability toward dysimmunity, the timing of which may be important determinants of neuropsychiatric illnesses as diverse as LNB, PANDAS and autism.

Viruses with cross-reactive epitopes to hepatitis B virus (HBV) and myelin basic protein, a constituent of myelin, develop autoimmune experimental allergic encephalomyelitis (EAE) due to circulating T-cells that preserve the memory of the virus and cross-react with myelin present in brain white matter of experimental mice. There is a form of post-infectious encephalitis named acute disseminated encephalomyelitis, an inflammatory demyelinating disorder of the brain in children that follows seemingly minor viral infection with a 2 to 30 days latency period that is thought to be post-infectious and autoimmune. It is believed that naissance of autoimmunity in such disorders originates when novel disease-inducing autoantigens are presented by specialized elements of the immune system in a tri-molecular complex comprised of antigen-presenting cells, major histocompatibility complex class II molecules and autoreactive $\mathrm{CD}^{4+} \mathrm{T}$-cells.

Bystander activation and killing, a second mechanism that can also lead to autoimmune disease, has gained support through the use of experimental animal models mirroring some of the features of autoimmune disease such as the non-obese diabetic mouse for type 1 diabetes (T1D) and EAE. It states that virus infections lead to significant activation of antigen presenting cells that potentially activate pre-primed autoreactive virus-specific T-cells that migrate to areas of virus infection/antigen such as the pancreas or brain. There, they encounter virus-infected cells presenting certain mole- 
cular tags, in turn releasing cytotoxic granules resulting in the killing or death of the infected cells. The dying cells, CD8+ T-cells and inflammatory cells within such inflammatory foci release cytokines that lead to the demise of uninfected neighboring cells and additional immunopathology at sites of infection.

Persistent viral infection is a third mechanism of immune-mediated injury due to the constant presence of viral antigens that in turn driving the immune response. Yet unproven in humans, an example of this occurs in experimental mice who develop a condition termed Theiler murine encephalomyelitis [15] in which persistent infection leads to a T-cell-mediated immunopathology in genetically susceptible animals. Susceptible strains develop virus-specific delayed type hypersensitivity responses while resistant strains do not. This response has been proposed as the basis for flaccid paralysis that spread rapidly to all four limbs after an incubation period of 7 to 30 days due to inflammation and demyelination in the brain and spinal cord.

\section{Medical Disorders}

\subsection{Spondyloarthropathy}

The relationship between microbial infection and the gut which has been known for decades as the basis for the SpA [16] has only recently been incorporated into the I-Cubed paradigm. SpA consists of diverse disorders of inflammatory arthritis. The reported incidence of 0.48 to $63 / 100,000$ and prevalence of $0.01 \%$ to $2.5 \%$ for SpA diseases in the population [17] varying depending upon on the methodology and case definitions used for case ascertainment, and frequency of HLA-B27 in the population studied. Affected patients with symptoms referable to the vertebral column and limb joints may be seen by a variety of specialists including rheumatologists, neurologists, and general practitioners before the disorder is correctly diagnosed. Documentation of the HLA B27 haplotype is a frequent associated feature. Experimentally-induced SpA occurs in mice with a striking resemblance to humans when HLA B27 components are introduced into genetically susceptible animals establishing its central role in the human sickness [18]. Certain genetically-prone mice develop colitis and later SpA when they are colonized with Bacterioides flora along with increased colonic cytokine expression compared to germ-free animals [19]. The story however became more interesting when it was found that such animals also showed activation of Th17 helper cells [20] with HLA-B27 misfolding and a further heightened immune response to the unfolded protein associated with interleukin-23 production [21]. Taken together, these findings suggested that genetically predisposed animals react to a microbial imbalance by altering their immune system in the intestinal compartment toward a more inflammatory state. The process is mediated by $\mathrm{T}$-cell and interleukin production which ultimately leads to local and systemic clinical disease manifested as a SpA-like human illness [22]. Such insights of the microbiomes have been used to advance therapy of SpA and other autoimmune arthritides. Empiric broad spectrum antibiotics do not appear to have a therapeutic role and may selected species with even more pathogenic potential. Bacterial modulation using alternative methods drawing from innate benefits of the microbi- 
ota [23] such as fecal microbial transplantation, diet and probiotics have instead been employed to restore a healthier intestinal microbiome.

\subsection{Type 1 Diabetes Mellitus}

T1D is associated with diverse metabolic processes that stem from hyperglycemia due to deficient secretion or action of insulin rendering them at perpetual risk for secondary neuropathic, ophthalmologic, renal and vascular disease. T1D usually develops before age 30 years and such individuals need insulin injections for the rest of their life. Their disease is caused by the gradual loss of insulin producing $\beta$-cells in the pancreas [24]. Patients with T2D are typically older, often obese, and at high risk for hypercholesterolemia and heart disease, with relative insulin resistance that perpetuates hyperglycemia. The epidemiology of diabetes is well known. In the U.S. alone, more than one million people are living with T1D and approximately 80 people per day, or 30,000 individuals per year, are newly diagnosed. The global incidence of T1D is increasing at a rate of approximately $3 \%$ to $4 \%$ per year, notably among younger children. These statistics highlight the need for both better TID therapies and the continued push towards the prevention of T1D.

In the past several years, several lines of investigations have suggested the importance of environmental factors including infectious diseases making T1D an important candidate for an I-Cubed framework of understanding:

First, T1D appears to be caused by autoimmune mechanisms directed against the insulin-producing $\beta$-cells of the pancreas [25] with up to $90 \%$ of T1D patients harboring or more autoantibodies.

Second, the pancreas of newly diagnosed T1D patients shows inflammation of the pancreas in the region of the insulin producing $\beta$-cells [26].

Third, the possibility that the onset of T1D might be triggered in genetically predisposed individuals by a preceding infection inducing attack on islets by molecular mimicry was investigated in T1D children who died prematurely. Their autopsy showed pancreatic islet cell, membrane-bound, superantigens indicating integrated bacterial or viral genes. The genetic risk of T1D is strongly linked to HLA class II DR3 and DR4 haplotypes, with the highest risk in those with the DR3/DR4 genotype. The importance of HLA genes to T1D risk highlights the role of the adaptive immune system in the development of autoimmunity.

Fourth, T1D occurs with increased frequency in association with several other autoimmune disorders, including Grave disease, pernicious anemia, Hashimoto thyroiditis, myasthenia gravis, anti-phospholipid antibody syndrome, and Addison disease.

Fifth, there is an animal model of autoimmune diabetes in which T-cells are strongly implicated in $\beta$-cell destruction, similar in nature to studies in human in which primed autoreactive T-cells recognize peptides common to both insulin and microbial antigens suggesting that molecular mimicry may be the priming event in the destruction of $\beta$-islet cells in animals and humans [27]. Moreover, the response of T-cells to homologous peptides derived from microbial antigens suggests that their initial priming 
could occur via molecular mimicry.

Sixth, it is hypothesized that perturbations in normal early microbiome development might pre-dispose to disease whether through direct modulation of innate immunity or via alteration of intestinal permeability, with a downstream effect on adaptive immunity. The gut microbiome is both less diverse and protective in individuals with islet cell autoimmunity or recent onset T1D [28]-[31]. Whether this difference is causal to T1D in such patients is not known since multiple factors could affect the early intestinal microbiome, some of which also have been shown to correlate with risk of islet autoimmunity and T1D [32]. Nevertheless, increased intestinal permeability as a consequence of prolonged enteric intestinal infections could lead to increased susceptibility to T1D [24]. Viruses, with their potential to induce innate and adaptive immune responses and local inflammation in the pancreas and other organs, have been suspected of initiating this autoimmune process. The etiologic link between T1D and viruses is based on epidemiological, serological, and histological findings, as well as experimental in vivo and in vitro studies in DNA Herpesviruses and Parvoviruses, and RNA Toga viruses, Paramyxoviruses, Retrovirusesand Picornaviruses. A mechanism of molecular mimicry has been suggested on the observation that some microbial/viral proteins and host proteins have sequence or structural homology and therefore go unrecognized as self-proteins stimulating immune response against the viral antigen which becomes cross-reactive against the homologous sequence of the host $\beta$-cellproteins [13] Another possible mechanism of infection-induced autoimmunity is bystander activation whereby the infection of neighboring $\beta$-cells stimulates local inflammation with the appearance of T-cells and other inflammatory cells that release inflammatory proteins that lead to bystander killing of $\beta$-cells [33]. Whatever the etiopathogenesis, there is a public health urgency to reduce the neuropathic, ophthalmologic, renal and vascular complications of T1D.

\subsection{Lyme Neuroborreliosis}

Lyme disease in humans is caused by the transmission of Borrelia (B.) burgdorferi in the bite of infected blacklegged Ixodes ticks. Typical symptoms include fever, headache, fatigue, and a characteristic skin rash called erythema migrans (EM). Undiagnosed and therefore untreated, infection disseminates to the nervous system causing LNB. The clinical diagnosis is based on symptoms, physical findings and the probability of exposure to infected ticks in endemic geographic areas, and confirmed by serological and cerebrospinal fluid (CSF) testing with the demonstration of intrathecal production of Borrelia-specific antibodies. There has been a general recognition for the potential of infectious-related autoimmune processes contributing to nervous system disease progression.

Originally named for Lyme and Old Lyme Connecticut wherein a tight clustering of recurrent attacks of childhood and adult asymmetric oligoarticular arthralgia occurred beginning in 1972, the disease showed a peak incidence of new cases in the summer and early fall. Epidemiologic analysis of the clustering suggested transmission of a causative agent by an arthropod vector to humans in whom $25 \%$ describe an expanding annular 
EM rash before onset of the arthritis. Cultures of the synovium and synovial fluid did not suggest infection with agents known to cause other forms of arthritis. Those who developed arthritis appeared to have significantly elevated ESR, lower third and fourth components of complement (C3, C4), higher serum IgM levels, and serum cryoprecipitates at the time of the skin lesions suggesting an active immunologic response. Five years later, Burgdorfer and colleagues [34] isolated a spirochete (Figure 1) from the tick Ixodes dammini that bound immunoglobulins of patients convalescing from Lyme disease and recorded the development of lesions resembling EM in New Zealand white rabbits 10 to 12 weeks after being fed upon by the ticks. One year later in the same volume of The New England Journal of Medicine, Steere and coworkers [35] and Benach and colleagues [36] described the spirochetal etiology of Lyme disease.

Lyme disease is the most commonly reported vector-borne illness and the fifth most common disease in the National Notifiable Diseases Surveillance System. Of interest has been the increase in the geographic distribution of incident cases in the U.S. over the past several years. Nonetheless, in 2013, 95\% of confirmed incident cases were reported from fourteen northeast and mid-western states including Connecticut, Delaware,

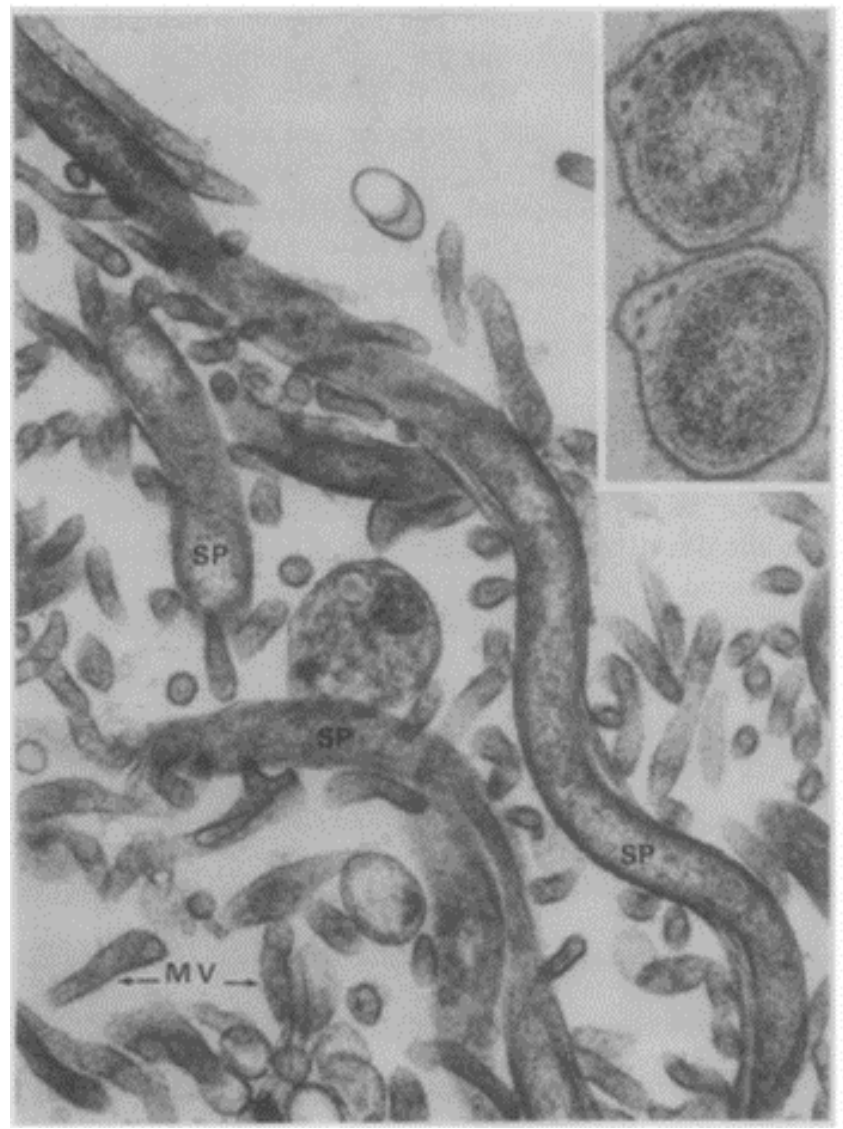

Figure 1. Electron micrograph of I. dammini spirochetes (SP) associated with microvillar brush border (MV) of the tick's midgut $(\mathrm{X} 55,440)$. Insert shows cross-section of spirochetes $(\mathrm{X} 122,100)$. 
Maine, Maryland, Massachusetts, Minnesota, New Hampshire, New Jersey, New York, Pennsylvania, Rhode Island, Vermont, Virginia and Wisconsin. The seasonal occurrence of Lyme disease follows the life cycle of Ixodes ticks. Children age 5 to 14 years and adult's age greater than 65 years are most susceptible when they engage in activities that heighten exposure to tick bites infected B. burgdorferi. Most cases occur from late spring to early fall when larval ticks mature into nymphs. Nymphs are infected by primary mammalian hosts transmitting the disease to secondary human hosts. Biodiverse habitats have reduced risk of Lyme disease. Clearing forests favor more efficient mammalian hosts such as mice spreading infection to people. Surveillance methods to ascertain cases of Lyme disease employ rigorous clinical and laboratory criteria to verify the diagnosis for reporting purposes, the results of which are verified and tabulated in final numbers in the Morbidity and Mortality Weekly Report (MMWR) in early August of the following year and summarized in the annual MMWR Summary of Notifiable Diseases. A CDC public use dataset provides the number of confirmed cases by county for the years 1992 to 2011 in 5-year intervals enabling investigators to access and download the information into compatible research-driven computer software for epidemiological analysis.

Inherent in the public health debate has been the contribution of infectious versus immune-mediated mechanisms to clinical manifestations and disease progression. Two approaches to LNB utilizing experimental animals and recognition of the importance of the blood-brain barrier (BBB) advanced understanding of the autoimmune manifestations of the human disease. Between 1998 and 1993 two animal models, the murine [37] and non-human primate [38] [39] accurately mimicked the microbiological, clinical, immunological, and neuropathological aspects of LNB. Two methods of spirochete inoculation, by needle injection of 1 million $\mathrm{N} 40 \mathrm{Br}$ strain spirochetes and feeding of infected ticks were found to be comparable in establishing infection. Transient immunosuppression maximized the yield of infection in some of the NHP. The CNS was a major reservoir of spirochetal infection and demonstrated that a strong, well-developed anti-Borrelia humoral immune response did not clear spirochetes from NHP during the months of infection. Accordingly, spirochetal presence was a necessary but not sufficient condition for inflammation. With the aim of evaluating whether inflammation induced by B. burgdorferi was causal in mediating the pathogenesis of acute LNB, investigators [40] studied the inflammatory changes induced in CNS, spinal nerves, and dorsal root ganglia (DRG) of rhesus macaques inoculated with live B. burgdorferi into the cisterna magna. Some animals were left untreated or given the anti-inflammatory drug dexamethasone a corticosteroid that inhibited the expression of several immune mediators and studied for either 8 or 14 weeks post-inoculation. Enzyme-linked immunosorbent assay (ELISA) of CSF showed significantly elevated levels of IL-6, IL-8, chemokine ligand 2, and CXCL 13 and pleocytosis in all infected animals, except dexamethasone-treated animals, however CSF and CNS tissues of infected animals were culture-positive for B. burgdorferi regardless of treatment. B. burgdorferi antigen was present in DRG and dorsal roots by immunofluorescence staining and confocal micro- 
scopy. Histopathology revealed leptomeningitis, vasculitis, and focal inflammation in the CNS; necrotizing focal myelitis in the cervical spine cord; radiculitis; neuritis and demyelination in spinal roots; and inflammation with neurodegeneration in the DRG that was concomitant with significant neuronal and satellite glial cell apoptosis. These changes were absent in the dexamethasone-treated animals in accordance with the hypothesis that effective suppression of inflammation by dexamethasone treatment resulted in inhibition of glial and neuronal damage. This in turn suggested that host immunity due to infection by $B$. burgdorferi with subsequent inflammation, and not infection alone, were causal in the pathogenesis of LNB.

Central to the question of active or chronic CNS infection is whether B. burgdorferi has disseminated to the CNS across the $\mathrm{BBB}$ and if there is intrathecal production of Borrelia-specific antibodies. The BBB is a neurovascular unit comprised of capillary vascular endothelial and neural cells, extracellular matrix components, and a variety of immune cells that has been intensely investigated in health and disease [41]-[43].

A schematized and electron microscopic appearance of cerebral capillaries in the BBB (Figure 2 and Figure 3) demonstrate layers of pericytes adherent to the abluminal or parenchymal surface of endothelial cells, together surrounded by a layer of basal lamina comprised of extracellular matrix protein molecules. The end feet of neighboring astrocyte processes ensheath the blood vessels. Monolayers of adjacent endothelial cells that form tight junctions (TJ) strands connect adjacent endothelial cells by adhesions of transmembrane (occludin, claudin, and junctional associated molecules [JAM]) across the intercellular space while cytoplasmic scaffolding and regulatory proteins such as zona occludens type 1 and 2 [ZO-1, ZO-2]) provide linkage to the actin cytoskeleton

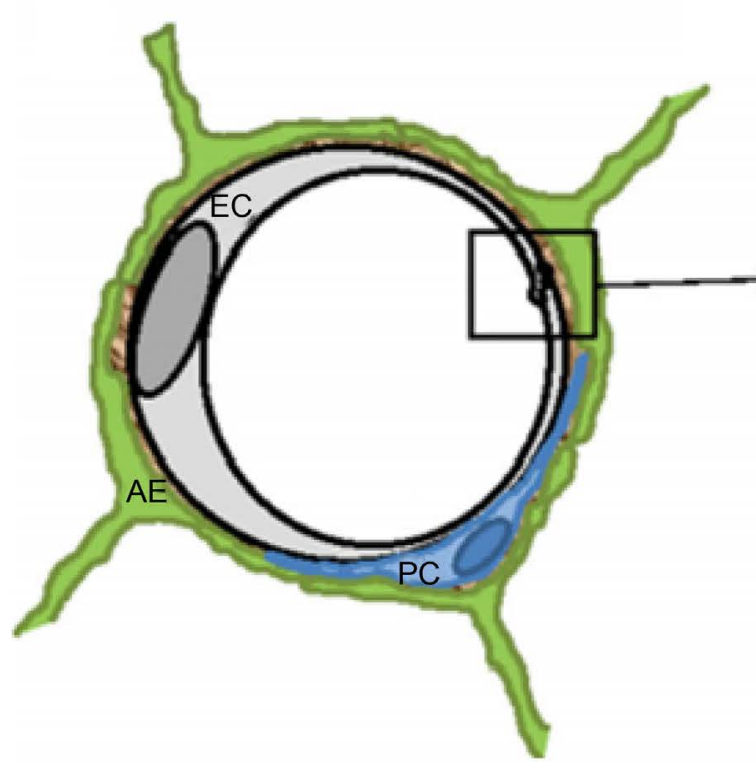

(a)

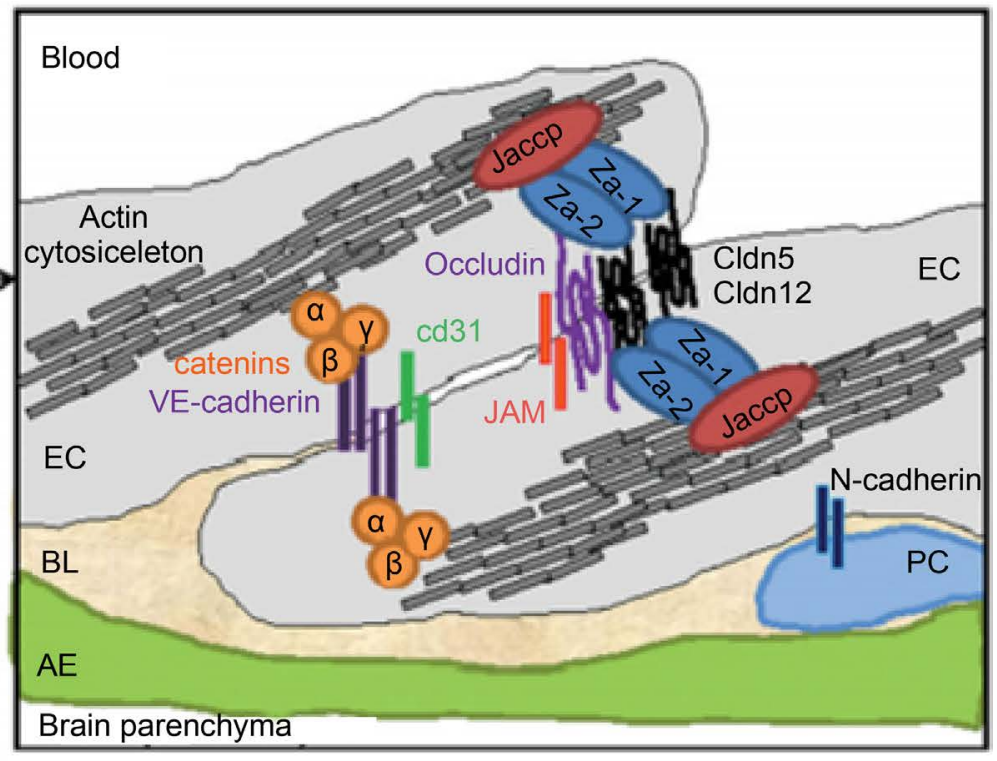

(b)

Figure 2. A. Cross-section schematic representation of a capillary in the human blood-brain barrier over an endothelial tight junction. B. The insert shows the molecular composition of tight and adherens junctions. See text for details. Reproduced from, Daneman R. The blood-brain barrier in health and disease. Ann Neurol 2012; 72:649, with permission of the publisher. 


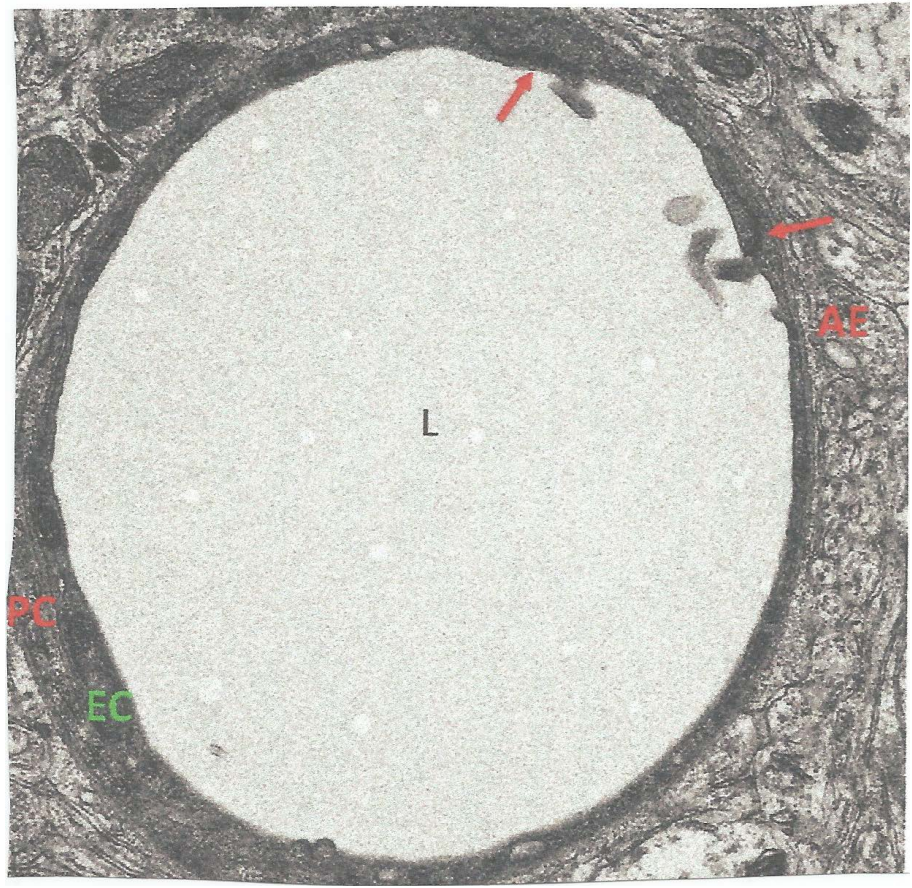

Figure 3. Electron micrograph of a capillary in the adult murine blood-brain barrier. Endothelial cells are held together by tight junctions (red arrow). Reproduced from, Daneman R. The blood-brain barrier in health and disease. Ann Neurol 2012, 72, 650, with permission of the publisher.

and initiate several signaling mechanisms via protein-protein interactions. Endothelial BBB cells are also linked by adherens junctions composed of vascular endothelial (VE)-cadherin, which mediates cell-cell adhesion interactions, linking adherens junctions to the actin cytoskeleton via catenins. Perivascular macrophages that reside between astrocyte end feet and the vessel wall, mast cells associated with specific regions of the CNS, resident microglia that act as antigen presenting cells (APC), and circulating leukocytes that penetrate the intact $\mathrm{BBB}$ via interactions with endothelial adhesion molecules (CAM) to mediate bidirectional crosstalk between immune cells and endothelium for normal surveillance, constitute the extended neurovascular unit. Recognizing that the mechanisms by which bacteremia can breach the BBB are still incompletely understood, a variety of microbial factors appear to act directly or indirectly to trigger production of endogenous inflammatory mediators to alter endothelial $\mathrm{TJ}$ and facilitate bacterial entry. The abnormal entry of plasma components, immune molecules and cellular elements across the BBB leads to further neural dysfunction and varying degrees of irreversible neural degeneration.

One approach to study the relative contributions of infection and post-infectious dysimmunity to LNB includes sampling the cerebrospinal fluid (CSF) and obtaining detailed functional neuroimaging of the brain in affected patients with Lyme encephalopathy (LE) analogous to a simple supply and demand relationship, respectively represented by cerebral perfusion imaging via nuclear medicine (NM) radioisotope single 
photon emission tomography (SPECT) and fluorodeoxyglucose (FDG) position emission tomography (PET) alone or fused with magnetic resonance imaging (MRI) of the brain for improved resolution. While common CSF findings in LNB include elevated protein content, normal glucose, lymphocytic pleocytosis, and humoral immune response composed of intrathecal immunoglobulins that depend upon the stage and activity of the disorder [44], intrathecal secretion of anti-B. burgdorferi-specific antibody is currently the best laboratory evidence of active LNB [45]. Multi-parametric magnetization transfers and diffusion tensor magnetic resonance imaging (MRI) [46] and high-field 3-D 1H+-MR spectroscopy coupled with non-localizing proton MR spectroscopy (1H-MRS), and three dimensional (3D) 1H-MRS at 3 tesla (T) have been used to examine an array of key brain metabolites including $\mathrm{N}$-acetylaspartate (NAA), an indicator of neuronal integrity [47] [48]. Preliminary studies of 3D-1H-MRS (TR/Te = $1800 / 35 \mathrm{~ms}$ ) in patients with CDC confirmed Lyme disease and CNS manifestations [48] found no differences between affected cases and controls in absolute NAA in whole brain or when gray and white matter were considered separately within the voxels of interest using a mixed model of analysis of variance (ANOVA). However, brain FDG-based proton- emission tomography (FDG-PET) useful in the evaluation of cognitive and memory disturbances in affected patients with LE, disclosed two patterns, temporal and parieto-temporal lobe hypometabolism and diffuse cortical hypometabolism, in which temporal lobe involvement was an important associated feature of the memory disturbance [49]. The close coupling of regional cerebral blood flow (rCBF) and cerebral metabolic rate (rCMR) in other affected patients enrolled in a case-control study of LE [50] that found no difference between study patients and controls in measurements of resting $\mathrm{rCBF}$ and $\mathrm{rCMR}$ except after hypercapnia challenge, nonetheless suggested that the observed regional abnormalities were primarily metabolically driven. MRI combined with PET imaging more effectively displays the area of hypometabolism (Figure 4). Logigian and colleagues [51] derived a perfusion deficit index (PDI) based upon acquired Tc-99m hexamethylpropyleneamine oxime (HMPAO) activity reflective of the number and severity of focal perfusion defectsin subcortical frontal and other cortical regions noting the highest values in those with definite LE (255, range 193-354) associated with either $B$. burgdorferi intrathecal antibody production or spirochetal DNA in CSF, or serological evidence of exposure by ELISA and Western blotting in serum with evidence of neuropsychological testing abnormalities that typically included memory disturbance and mild depression. The authors concluded that LE patients could be distinguished by the presence of hypoperfusion defects in subcortical and cortical structures that partially reversed after intravenous antibiotics. Most authorities consider NM brain SPECT a useful predictor of BBB integrity due to either acute, subacute or chronic infection, or the sequela of post-infectious autoimmunity. Patients with presumptive or definite LNB may be distinguished by a variety of cortical hypoperfusion deficits that may be generalized or heterogeneous in both hemispheres, localized to a single hemisphere, cortical or subcortical region (Figure 5). However, there has not been a systematic analysis of the sensitivity or specificity of NM brain SPECT 


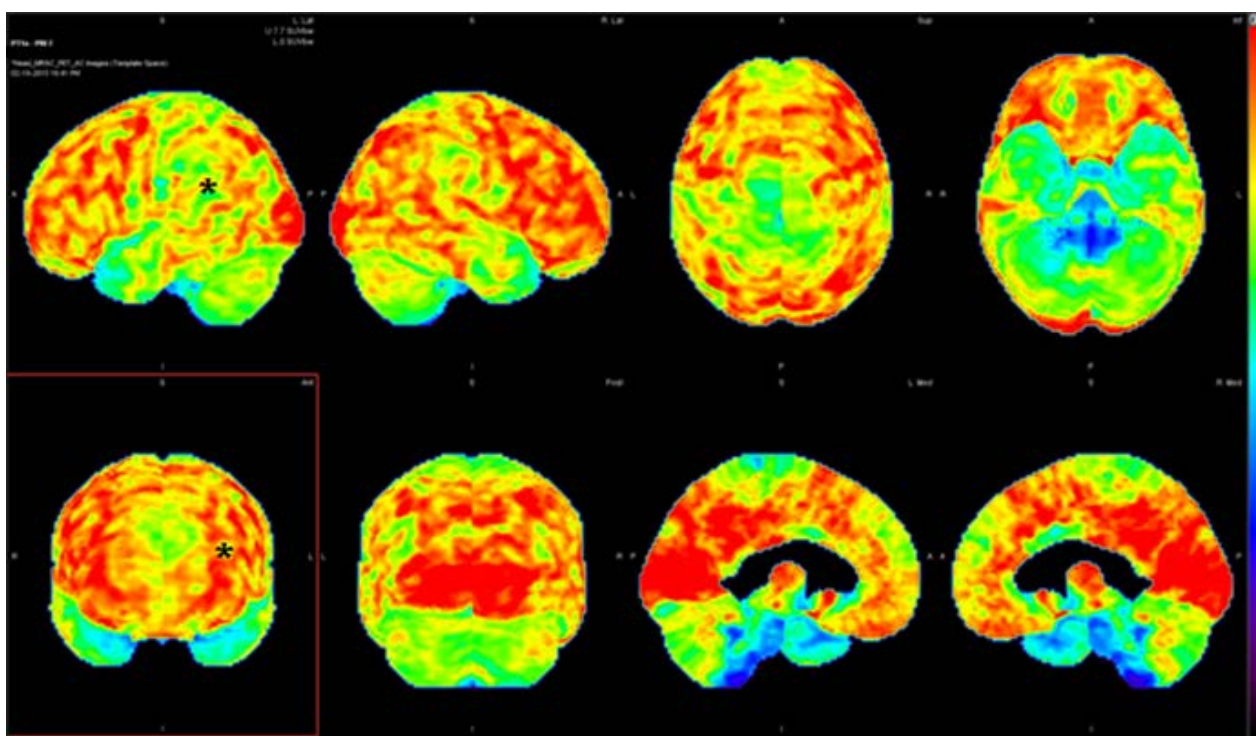

Figure 4. Magnetic resonance imaging (MRI) combined with fluorodeoxyglucose positron emission tomography (FDG-PET). A 12-year-old girl with memory disturbance. There is hypometabolism of the left temporoparietal regions $\left(^{\star}\right)$.

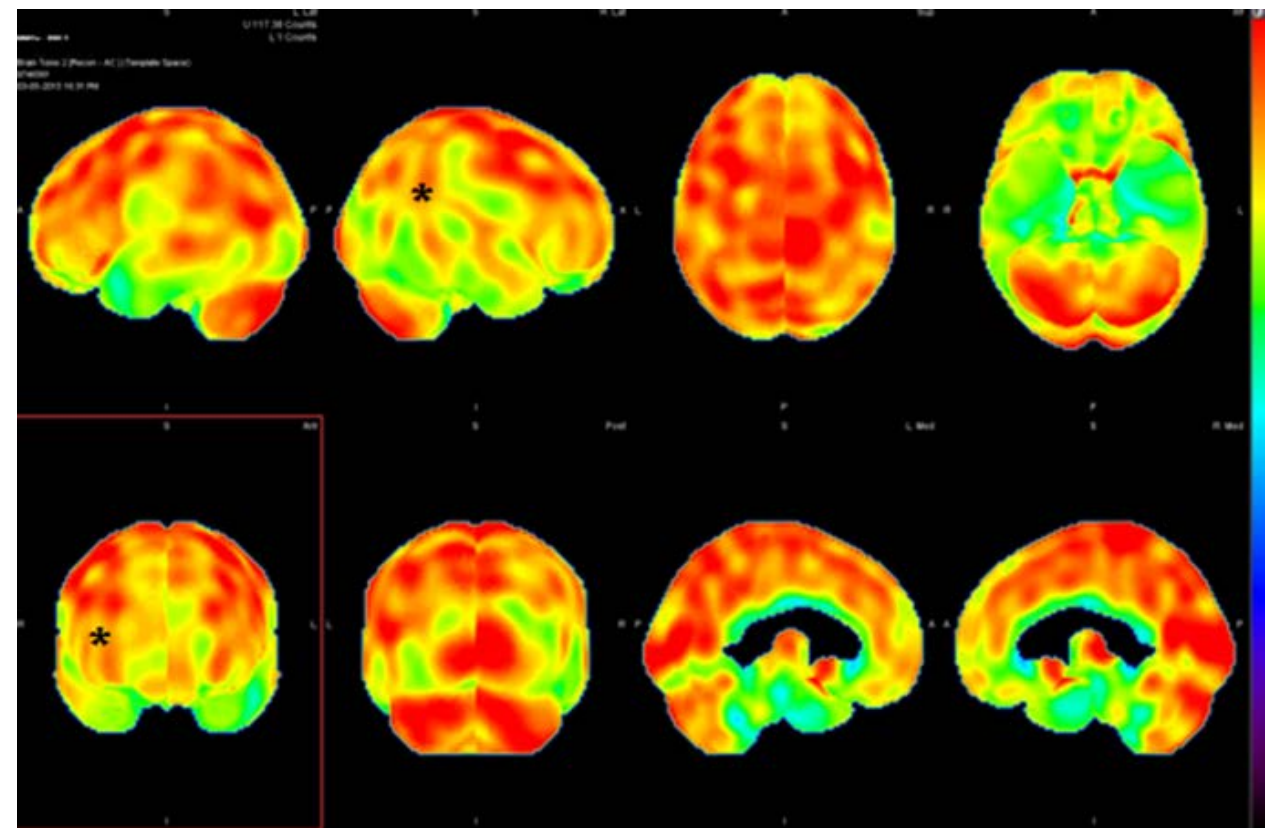

Figure 5. Nuclear medicine cerebral perfusion (brain) single photon emission tomography (SPECT). A 17-year-old girl with Lyme encephalopathy and memory disturbance. There is hypoperfusion of the right parietotemporal regions $\left({ }^{*}\right)$.

in LNB nor has it been adequately studied in well- defined cohorts of LNB.

\section{PANDAS}

Between 1989 and 1998, Swedo and investigators [52]-[55] described children and adolescents with obsessive-compulsive disorders (OCD) revealing acute symptom exacer- 
bations with group A $\beta$-hemolytic streptococcal (GABHS) infection. Like rheumatic fever, the authors [55] postulated an etiopathogenesis of PANDAS in genetically and developmentally susceptible host due to GABHS exposure with a resulting CNS extrapyramidal immune response. Since that time there has been increasing interest in recognizing the immunologic aspects of PANDAS. Elevated anti-streptolysin (ASO) antibodies distinguished cases versus non-cases respectively in $59 \%$ and $37 \%(p=0.03)$ of affected children. A B-cell alloantigen identified by monoclonal antibodies as D8/D17 [56] which attaches to the surface of B cells as a susceptibility factor for rheumatic fever, has been noted in $85 \%$ of patients with PANDAS, yet in only $17 \%$ of normal controls [57]. The GNcNAc epitope expressed in SC monoclonal antibodies (mAb) provokes a strong humoral response during and after active streptococcal infection [58] [59] as a result of terminal O-linked GLcNAc residues that show structural similarity to host glycoconjugates. Moreover, experimental animals immunized with GlcNAc mAb leads to a T-cell dependent specific antibody response [60]. Anti-ganglioside antibodies mediate signal transduction pathways in cultured neuroblastoma cells [61] [62] and trigger calcium/calmodulin-dependent protein (CaM) kinase II activation [58]. Active PANDA serum IgG reacts with GlcNAc epitopes of GABHS GAC and lysoganglioside GM1 inducing CaM kinase II activity in human neuroblastoma cells suggesting the contribution of antibody-mediated neuronal cell signaling mechanisms in the development of PANDAS.

Equally compelling support for an immune-mediated pathogenesis in PANDAS has been derived from the result of immunomodulatory therapy in ameliorating the neuropsychiatric symptoms of affected children. Younger and Chen summarized the literature of PANDAS treated with intravenous immune globulin (IVIg) therapy based on seven articles [63]-[69] comprising an observational study (114 patients) [69], a randomized control trial (9 patients) [63], four small case series (21 patients) [65]-[68], and a single case abstract [64], together documenting the experience of 145 published children who met established criteria for the diagnosis of PANDAS [55] and were treated with IVIg therapy for neuropsychiatric symptoms. An analysis of their findings was performed contrasting and combining clinical characteristics and outcomes of cases in each study, and generalizing information with mean values for continuous variables and percentages for character values. Overall, $60 \%$ of children showed overall clinical improvement, $24 \%$ achieved remission of neuropsychiatric symptoms at final assessment, $9 \%$ were unchanged, and none were worse following IVIg therapy at doses between 1.0 and 2.0 grams per kilogram administered every 1 to 2 months for a mean duration of 15.3 months (range 0.03 - 61.79 months) for refractory neuropsychiatric symptoms associated with PANDAS. Of 22 patients (19.3\%) who achieved remission, all 22 (100\%) had low baseline IgG (20 patients) or IgG subclass levels (2 patients), alone (8 patients) or together (6 patients) or in association with reduced IgA or IgM levels (8 patients), indicative of humoral deficiency prior to IVIg treatment. One other reported patient who achieved remission status [10] had combined IgG2/4 subclass deficiency. The authors concluded that children with PANDAS with baseline humoral 
immune deficiency derived a favorable response to IVIg in PANDAS at 12 months follow-up consistent with its role in Ig replacement and immune modulation. Future research needs to focus on the selection of patients with PANDAS for treatment as well as the most effective regimen of IVIg.

\section{Autism}

Autism, the prototypic pervasive developmental disorder (PDD), is usually apparent by 3 years of age. It is characterized by a triad of limited or absent verbal communication, a lack of reciprocal social interaction or responsiveness, and restricted, stereotypic, and ritualized patterns of interests and behavior [70]. Autism spectrum disorder is a broader phenotype encompassing the less severe disorders Asperger syndrome and PDD not otherwise specified (PDD-NOS). The broad autism phenotype includes individuals with some symptoms of autism, but who do not meet the full criteria for autism or other disorders. Mental retardation coexists in approximately two-thirds of individuals with ASD, except for Asperger syndrome, in which mental retardation is conspicuously absent. ASD shows a striking sex bias with a male: female ratio of idiopathic autism estimated at 4-10:1, and an increase in this ratio as the intelligence of the affected individual's increases.

The prevalence of childhood autism and ASD, and the resultant life-long developmental disabilities increased 20- to 30-fold in epidemiological studies in the decades leading up to 2000, estimating a prevalence rise from 1 in 2500 children (0.04\%) [71] in the late 1960 s to $2 \%$ of vaccination-eligible age children [72]. However, such studies were difficult to interpret due to parent-reporting methodology and disputed by medical authorities to the despair of concerned parent activist groups. In the U.S. the CDC Autism and Developmental Disabilities Monitoring Network has been tracking the prevalence of ASD noting a $29 \%$ higher overall prevalence $[11.3$ per $1000(95 \% \mathrm{CI}=$ 11.0 - 1.7) in 2008 to 14.7 per $1000(95 \% \mathrm{CI}=14.3-15.1)$ in 2010] [73] also without a clear explanation. Wazana and colleagues [74] used a prediction analysis, to calculate how broadening diagnostic criteria, younger age at diagnosis, and improved efficiency of case ascertainment could produce temporal trends in the incidence and prevalence of autistic disorders noting that time trend studies showed an increase as large as 11.0-fold over a 13-year period, while conservative changes in the three methodological factors produced increases in the frequency of autistic disorders ranging from 2.1- to 28.8-fold.

The global burden of ASD was estimated for the Global Burden of Disease Study 2010 (GBD2010) [75] using pooled prevalence, incidence, remission and mortality risk data and Bayesian meta-regression approach adjusting for between-study variance to derive prevalence models. Burden was calculated in terms of years lived with disability (YLDs) and disability-adjusted life-years (DALYs) and reported by world regions for 1990 and 2010. The authors noted an estimated 52 million cases of ASD equating a prevalence of 7.6 per 1000 or 1 in 132 persons. After accounting for mythological variations, there was no evidence of a change in prevalence for ASD between 1990 and 2010, with little regional worldwide variation in prevalence. Globally, ASD accounted for 
more than 58 DALYs per 100,000 populations.

Historically, autism drew the attention of investigators when in the U.K. between 1998 and 1999, Andrew Wakefield and colleagues [76]-[78] studied a cohort of children with the combination of ileocolonic lymphoid nodular hyperplasia, persistent measles virus $\mathrm{N}$-protein in follicular dendritic cells of reactive ileal lymphoid tissue; colitis, subtle immunodeficiency, and elevated measles immunoglobulin G (IgG) immunoreactivity. So called "autistic enterocolitis" was attributed to immune conditioning by early viral vaccination. While there was agreement that vaccines employing an attenuated version of the virus was insufficient to induce frank infection, it was still processed by the immune system as if an infection were present, inducing a state of immunity with autism arising as a complication. Although Wakefield's studies were later discredited because of his association with parents seeking damages in on-going law suits over the MMR vaccine, several questions remained unanswered including the significance of viral traces in the gut lining to wild-type infection or vaccination, and the association of gastrointestinal disease with autism as his small case series of 12 children contained both biases of case ascertainment and information reporting.

The past several years have yielded a wealth of insight into these unanswered questions. In 2014, Hooker [79] reanalyzed the CDC data used in an earlier publication by DeStefano and colleagues [80] on the timing of the first MMR vaccine and the diagnosis of autism. Using a Pearson's chi-squared method to assess relative risk of receiving an autism diagnosis within the total cohort of as well as among different race and gender categories, the risk for males in general and African American males in particular showed odds ratios (OR) respectively of $1.69(\mathrm{p}=0.0138)$ and $3.36(\mathrm{p}=0.0019)$, with African American male OR of $1.73(\mathrm{p}=0.02)$ for autism cases in children receiving their first MMR vaccine prior to 24 months of age versus 24 months of age and thereafter. The study by DeStefano and colleagues [80] which employed conditional logistic regression dichotomized for three age cut-offs at 18, 24, and 36 months for receipt of the vaccination, was unable to ascertain a relation of MMR vaccination and development of autism in the cohort compared to controls, noting no contribution of sex. However, that study did not specifically examine African American race since the latter was used in matching the study cohort with controls. The Editor and Publisher of Translational Neurodegeneration subsequently retracted the Hooker article citing undeclared competing interest on the part of the peer review process and questions about the validity of the methods and statistical analyses [81]. A later population-based study [82] and a recent meta-analysis of case-control and cohort studies [83] found no strong evidence for an association between autism and MMR vaccination.

A case-control study [84] found that vaccinated children with autism and gastrointestinal disturbances were no more likely than age-matched children undergoing clinically-indicated ileocolonoscopy to have measles virus RNA or inflammation in bowel tissues, nor was the onset of autism or gastrointestinal disturbances temporally related to receipt of a MMR vaccine. Interestingly, measles virus $\mathrm{F}$ gene and $\mathrm{H}$ gene RNA were found in ileal biopsy tissue one boy with autism and gastrointestinal disturbances simi- 
larly in another boy of the control group corresponding to a real-time PCR range of 2 7 molecules per PCR reaction or approximately 50 - 500 measles virus RNA molecules per $100 \mathrm{ng}$ of total RNA extract, sequence analysis of which confirmed that the products were authentic. Both subjects had reactive small and large intestine lymphoid follicles. or those with gastrointestinal disturbances alone. Nonetheless, children with ASD in the Norwegian Motherand Child Cohort Study (MoBa) [85] were at significantly increased odds of maternally reported gastrointestinal disturbances including constipation, food allergies, food intolerance, diarrhea, and constipation. Although the early reports of Wakefield and colleagues [76]-[78] may have muddied the waters considerably, there has been subsequent evidence of alterations of the intestinal barrier in patients with autism spectrum disorders and in their first-degree relatives [86] and inflammation in the gastrointestinal tract of children with ASD including immune cell infiltrates in the small and large intestine, as well as increased T-cell activation in the intestinal mucosa compared to controls, that contribute to decreased mucosal integrity or leaky gut [67]. Active maternal infection and maternal immune activation in the absence of a pathogen lead to cardinal symptoms of autism in affected offspring of immune-activated dams in experimental animal models of childhood autism [88] [89].

Apart from the impact of infection and autoimmunity, autism has been associated with maternal age $>35$ years alone [90] or in those with foreign citizenship, use of medications during pregnancy, and among children with low birth weight and congenital malformations [91]; slowly advancing [92] or 10-year increased in maternal and paternal age [93], paternal age $>40$ years and being first-born of two older parents [94]; underlying genetic factors and obstetric complications [95]; maternal disease exposure to drugs, substance abuse, folic acid deficiency; pesticides, and air pollution [96]. The Autism Birth Cohort (ABC) [97] was established to address the natural history of ASD and to explore genetic and pre- or perinatal environmental factors in causation, as well as the interplay between genes and environment, and to facilitate discovery of biomarkers with potential to enable early recognition and treatment.

Current thinking now is that multiple potential risk factors, maternal, pre- and post-natal, and environmental including inflammatory autoimmune insults superimposed upon a genetically vulnerable substrate, can trigger the aberrant neuronal development characterizing autism. In support of the latter is absence of postmortem and neuroimaging signs of neurodegeneration in affected cases [98]. Genetic susceptibility for autism have been clearly established with chromosomal loci and associated Online Mendelian Inheritance in Man (OMIM) [99] phenotypes described at 7q22 (AUTS1; 608,636), 13q14 (AUTS; 608,049), 15q11 (AUTS4; 608,636), 2q (AUTS5; 606,053), 17q11 (AUTS6; 609,378), 17q21 (AUTS7; 610,676), 3q25-q27 (AUTS8; 607,373), 7q31 (AUTS9; 611,015), 7q36 (AUTS10; 611,016), 1q41 (AUTS11; 610,836), 21p13-q11 (AUTS12; 610,838), 12q14 (AUTS13; 610,908), 16p11.2 (AUTS14A; 611,913); and 16p11.2 (AUTS14B; 614,671); and at 7q35-q36 with mutation of CNTNAP2 (AUTS15; 612,100); 3q24 with mutation of SLC9A9 (AUTS16; 613,410); 11q13 with mutation of SHANK2 (AUTS17; 613,436); and with mutation of CHD8 (AUTS18; 615,032) illu- 
strating the inherent potential variability.

Future directions in autism have focused on the potential benefit of immunomodulatory therapy in children with abnormal serum titers of autoantibodies autoreactive against the CNS, precipitous worsening after vaccination suggesting an overly robust immune response; disturbed cell mediated or humoral immunity [100] and concurrence with an overtly dysimmune disorder such as PANDAS [71] for which immune modulatory therapy with IVIg may be appropriate [101].

\section{Conclusion}

Medical science is just now realizing the full importance of the microbial world. Thanks to genetic advances such as low-cost high-throughput sequencing of microbial communities comprising the human microbiome, the identity and function of unculturable microbes is being unveiled. Beyond improved microbial cataloguing, we are learning that human beings are superorganisms integrating the identity, function, and immunity of resident bacteria, yet prepared throughout our own innate and adaptive immune systems and modified by genetic and environmental factors, to deal with invading organisms. Protective immunity becomes the source of autoimmunity through a variety of well-established mechanisms. Public health officials and neuroepidemiology researchers will be called upon to guide the understanding of I-Cubed illnesses and the implications of the human microbiome for communicable and non-communicable diseases, at times one leading to the other, as the natural history is appreciated and the responsiveness of given medical and neurological disorder to a variety of medical approaches including strong antibiotics and immune-modulatory is established

\section{References}

[1] Regidor, E., de la Fuente, L., Gutierrez-Fisac, J.L., et al. (2007) The Role of the Public Health Official in Communicating Public Health Information. American Journal of Public Health, 97, S93-S97. http://dx.doi.org/10.2105/ajph.2006.094623

[2] Lederberg, J. and McCray, A.T. (2001) 'Ome Sweet 'Omics-A Genealogical Treasury of Words. Scientist, 15, 8 .

[3] Alivisator, A.P., Blaser, M.J., Brodie, E.L., et al. (2015) A Unified Initiative to Harness Earth's Microbiomes. Science, 350, 507-508. http://dx.doi.org/10.1126/science.aac8480

[4] Dubilier, N., McFall-Ngai, M. and Zhao, L. (2015) Create a Global Microbiome Effort. Nature, 526, 631-634. http://dx.doi.org/10.1038/526631a

[5] Relman, D.A., Schmidt, T.M., MacDermott, R.P., et al. (1992) Identification of the Uncultured Bacillus of Whipple's Disease. New England Journal of Medicine, 327, 293-301. http://dx.doi.org/10.1056/NEJM199207303270501

[6] Fredericks, D.N. and Relman, D.A. (2001) Localization of Tropheryma whippelii rRNA in Tissues from Patients with Whipple's Disease. Journal of Infectious Diseases, 183, 12291237. http://dx.doi.org/10.1086/319684

[7] Relman, D.A. (1999) The Search for Unrecognized Pathogens. Science, 284, 1308-1310. http://dx.doi.org/10.1126/science.284.5418.1308

[8] Lower, R., Lower, J. and Kurth, R. (1996) The Viruses in All of Us: Characteristics and Biological Significance of Human Endogenous Retrovirus Sequences. Proceedings of the Na- 
tional Academy of Sciences of the United States of America, 93, 5177-5184.

http://dx.doi.org/10.1073/pnas.93.11.5177

[9] Hajjeh, R.A., Relman, D., Cieslak, P.R., et al. (2002) Surveillance for Unexplained Deaths and Critical Illnesses Due to Possibly Infectious Causes, United States, 1995-1998. Emerging Infectious Diseases, 8, 145-153. http://dx.doi.org/10.3201/eid0802.010165

[10] Gao, S.J. and Moore, P.S. (1996) Molecular Approaches to the Identification of Unculturable Infectious Agent. Emerging Infectious Diseases, 2, 159-167.

http://dx.doi.org/10.3201/eid0203.960301

[11] Han, Y.W., Shi, W., Huang, G.T., et al. (2000) Interactions between Periodontal Bacteria and Human Oral Epithelial Cells: Fusobacterium nucleatum Adheres to and Invades Epithelial Cells. Infection and Immunity, 68, 3140-3146.

http://dx.doi.org/10.1128/IAI.68.6.3140-3146.2000

[12] Prorok-Hamon, M., Friswell, M.K., Alswied, A., et al. (2014) Colonic Mucosa-Associated Diffusely Adherent afaC+Escherichia coli Expressing IpfA and pks Are Increased in Inflammatory Bowel Disease and Colon Cancer. Gut, 63, 761-770. http://dx.doi.org/10.1136/gutjnl-2013-304739

[13] Fujinami, R.S., von Herrath, M.G., Christen, U., et al. (2006) Molecular Mimicry, Bystander Activation, or Viral Persistence: Infections and Autoimmune Disease. Clinical Microbiology Reviews, 19, 80-94. http://dx.doi.org/10.1128/CMR.19.1.80-94.2006

[14] Hornig, M. (2013) The Role of Microbes and Autoimmunity in the Pathogenesis of Neuropsychiatric Illness. Current Opinion in Rheumatology, 25, 488-495. http://dx.doi.org/10.1097/BOR.0b013e32836208de

[15] Theiler, M. (1937) Spontaneous Encephalomyelitis of Mice: A New Virus Disease. Journal of Experimental Medicine, 65, 705-719. http://dx.doi.org/10.1084/jem.65.5.705

[16] Yurkovetskiy, L.A., Pickard, J.M. and Chervonsky, A.V. (2015) Microbiota and Autoimmunity: Exploring New Avenues. Cell Host \& Microbe, 17, 548-552. http://dx.doi.org/10.1016/j.chom.2015.04.010

[17] Stolwijk, C., Boonen, A., van Tubergen, A. and Reveille, J.D. (2012) Epidemiology of Spondyloarthritis. Rheumatic Diseases Clinics of North America, 38, 441-476. http://dx.doi.org/10.1016/j.rdc.2012.09.003

[18] Hammer, R.E., Maila, S.D., Richardson, J.A., et al. (1990) Spontaneous Inflammatory Disease in Transgenic Rates Expressing HLA-B27 and Human Beta 2 m: An Animal Model of HLA-B27-Associated Human Disorders. Cell, 63, 1099-1112. http://dx.doi.org/10.1016/0092-8674(90)90512-D

[19] Rath, H.C., Herfarth, H.H., Ikeda, J.S., et al. (1996) Normal Luminal Bacteria, Especially Bacteriodes Species, Mediated Chronic Colitis, Gastritis, and Arthritis in HLA-B27/Human Beta2 Microglobulin Transgenic Rats. Journal of Clinical Investigation, 98, 945-953. http://dx.doi.org/10.1172/JCI118878

[20] Glatigny, S., Fert, I., Blaton, M.A., et al. (2012) Proinflammatory Th17 Cells Are Expanded and Induced by Dendritic Cells in Spondyloarthritis-Prone HLA-B27-Transgenic Rats. Arthritis \& Rheumatology, 64, 110-120. http://dx.doi.org/10.1002/art.33321

[21] DeLay, M.L., Turner, M.J., Klenk, E.I., et al. (2009) HLA-B27 Misfolding and the Unfolded Protein Response Augment Interleukin-23 Production and Are Associated with Th17 Activation in Transgenic Rats. Arthritis \& Rheumatology, 60, 2633-2643.

http://dx.doi.org/10.1002/art.24763

[22] Scher, J.U., Littman, D.R. and Abramson, S.B. (2015) Microbiome in Inflammatory Arthritis and Human Rheumatic Diseases. Arthritis \& Rheumatology, 68, 35-45. 
http://dx.doi.org/10.1002/art.39259

[23] Olle, B. (2013) Medicines from Microbiota. Nature Biotechnology, 31, 309-315. http://dx.doi.org/10.1038/nbt.2548

[24] Precechtelova, J., Borsanyiova, M., Sarmirova, S., et al. (2014) Type I Diabetes Mellitus: Genetic Factors and Presumptive Enteroviral Etiology or Protection. Journal of Pathogens, 2014, Article ID: 738512. http://dx.doi.org/10.1155/2014/738512

[25] Atkinson, M.A. and Caclaren, N.K. (1994) The Pathogenesis of Insulin-Dependent Diabetes Mellitus. New England Journal of Medicine, 331, 1428-1436.

http://dx.doi.org/10.1056/NEJM199411243312107

[26] Hanninen, A., Jolkanen, S., Salmi, M., et al. (1992) Macrophages, T Cell Receptor Usage, and Endothelial Cell Activation in the Pancreas at the Onset of Insulin-Dependent Diabetes Mellitus. Journal of Clinical Investigation, 90, 1901-1910. http://dx.doi.org/10.1172/JCI116067

[27] Yang, J., Chow, I.T., Sosinowski, T., et al. (2014) Autoreactive T Cells Specific for Insulin B: 11-23 Recognize a Low-Affinity Peptide Register in Human Subjects with Autoimmune Diabetes. Proceedings of the National Academy of Sciences of the United States of America, 111, 14840-14845. http://dx.doi.org/10.1073/pnas.1416864111

[28] Giongo, A., Gano, K.A., Crabb, D.B., et al. (2011) Toward Defining the Autoimmune Microbiome for Type 1 Diabetes. ISME Journal, 5, 82-91. http://dx.doi.org/10.1038/ismej.2010.92

[29] Bordon, Y. (2015) Autoimmunity: The bug Eye Bandits. Nature Reviews Immunology, 15, 595. http://dx.doi.org/10.1038/nri3911

[30] Brown, C.T., Davis-Richardson, A.G., Giongo, A., et al. (2011) Gut Microbiome Metagenomics Analysis Suggests a Functional Model for the Development of Autoimmunity for Type 1 Diabetes. PLoS ONE, 6, e25792. http://dx.doi.org/10.1371/journal.pone.0025792

[31] De Goffau, M.C., Luopajarvi, K., Knip, M., et al. (2013) Fecal Microbiota Composition Differs between Children with Beta-Cell Autoimmunity and Those without. Diabetes, 62, 1238-1244. http://dx.doi.org/10.2337/db12-0526

[32] VanBuecken, D., Lord, S. and Greenbaum, C.J. (2015) Changing the Course of Disease in Type 1 Diabetes. In: De Groot, L.J., Beck-Peccoz, P., Chrousos, G., et al., Eds., Endotext, MDText.Com Inc., South Dartmouth.

[33] Roep, B.O., Hiemstra, S., Schloot, N.C., et al. (2002) Molecular Mimcry in Type 1 Diabetes: Immune Cross Reactivity between Islet Autoantigen and Human Cytomegalovirus but Not Coxsackie Virus. Annals of the New York Academy of Sciences, 958, 163-165. http://dx.doi.org/10.1111/j.1749-6632.2002.tb02961.x

[34] Burgdorfer, W., Barbour, A.G., Hayes, S.F., et al. (1982) Lyme Disease-A Tick-Borne Spirochetosis? Science, 216, 1317-1319. http://dx.doi.org/10.1126/science.7043737

[35] Steere, A.C., Grodzicki, R.I., Kornblatt, A.N., et al. (1983) The Spirochetal Etiology of Lyme Disease. New England Journal of Medicine, 308, 733-740. http://dx.doi.org/10.1056/NEJM198303313081301

[36] Benach, J.I., Bosler, E.M., Hanrahan, J.P., et al. (1983) Spirochetes Isolated from the Blood of Two Patients with Lyme Disease. New England Journal of Medicine, 308, 740-742. http://dx.doi.org/10.1056/NEJM198303313081302

[37] Barthold, S.W., Moody, K.D., Terwillinger, G.A., et al. (1988) Experimental Lyme Arthritis in Rats Infected with Borrelia burgdorferi. Journal of Infectious Diseases, 157, 842-846. http://dx.doi.org/10.1093/infdis/157.4.842 
[38] Pachner, A.R., Delaney, E., O’Neill, T., et al. (1995) Inoculation of Nonhuman Primates with the N40 Strain of Borrelia burgdorferi Leads to a Model of Lyme Neuroborreliosis Faithful to the Human Disease. Neurology, 45, 165-172.

http://dx.doi.org/10.1212/WNL.45.1.165

[39] Pachner, A.R., Delaney, E. and O’Neill, T. (1995) Neuroborreliosis in the Nonhuman Primate: Borrelia burgdorferi Persists in the Central Nervous System. Annals of Neurology, 38, 667-669. http://dx.doi.org/10.1002/ana.410380417

[40] Ramesh, G., Didier, P.J., England, J., et al. (2015) Inflammation in the Pathogenesis of Lyme Neuroborreliosis. American Journal of Pathology, 185, 1344-1360. http://dx.doi.org/10.1016/j.ajpath.2015.01.024

[41] Benarroch, E.E. (2012) Blood-Brain Barrier. Neurology, 78, 1268-1276. http://dx.doi.org/10.1212/WNL.0b013e318250d8bc

[42] Hawkins, B.R. and Davis, T.P. (2005) The Blood-Brain Barrier/Neurovascular Unit in Health and Disease. Pharmacological Reviews, 57, 173-185. http://dx.doi.org/10.1124/pr.57.2.4

[43] Weiss, N., Miller, F., Cazaubon, S., et al. (2009) The Blood-Brain Barrier in Brain Homeostasis and Neurological Diseases. Biochimica et Biophysica Acta, 1788, 842-857. http://dx.doi.org/10.1016/j.bbamem.2008.10.022

[44] Sindern, E. and Malin, J.P. (1995) Phenotypic Analysis of Cerebrospinal Fluid over the Course of Lyme Meningoradiculitis. Acta Cytologica, 39, 73-75.

[45] Hansen, K., Crone, C. and Kristoferitsch, W. (2013) Lyme Neuroborreliosis. Handbook of Clinical Neurology, 115, 559-575. http://dx.doi.org/10.1016/B978-0-444-52902-2.00032-1

[46] Agosta, F., Rocca, M.A., Beneditti, B., et al. (2006) MR Imaging Assessment of Brain and Cervical Cord Damage in Patients with Neuroborreliosis. American Journal of Neuroradiology, 27, 892-894.

[47] Rigotti, D.J., Inglese, M. and Gonen, O. (2007) Whole-Brain N-Acetylaspartate as a Surrogate Marker of Neuronal Damage in Diffuse Neurological Disorders. American Journal of Neuroradiology, 28, 1843-1849. http://dx.doi.org/10.3174/ajnr.A0774

[48] Younger, D.S., Wu, W.E., Hardy, C., Perry, N. and Gonen, O. (2012) Lyme Neuroborreliosis and Proton MR Spectroscopy: Preliminary Results from an Urban Referral Center Employing Strict CDC Criteria for Case Selection (P03.246). Neurology, 78, P03.246.

[49] Newberg, A., Hassan, A. and Alavi, A. (2002) Cerebral Metabolic Changes Associated with Lyme Disease. Nuclear Medicine Communications, 23, 773-777. http://dx.doi.org/10.1097/00006231-200208000-00011

[50] Fallon, B.A., Lipkin, R.B., Corbera, K.M., et al. (2009) Regional Cerebral Blood Flow and Metabolic Rate in Persistent Lyme Encephalopathy. Archives of General Psychiatry, 66, 554-563. http://dx.doi.org/10.1001/archgenpsychiatry.2009.29

[51] Logigian, E.L., Johnson, K.A., Kijewski, M.F., et al. (1997) Reversible Cerebral Hypoperfusion in Lyme Encephalopathy. Neurology, 49, 1661-1670. http://dx.doi.org/10.1212/WNL.49.6.1661

[52] Swedo, S.E., Rapoport, J.L., Leonard, H.L., Lenane, M. and Cheslow, D. (1989) Obsessive-Compulsive Disorder in Children and Adolescents: Clinical Phenomenology of 70 Consecutive Cases. Archives of General Psychiatry, 46, 335-341. http://dx.doi.org/10.1001/archpsyc.1989.01810040041007

[53] Leonard, H.L., Lenane, M.C., Swedo, S.E., et al. (1992) Tics and Tourette's Syndrome: A 2 to 7-Year Followup of 54 Obsessive-Compulsive Children. American Journal of Psychiatry, 149, 1244-1251. http://dx.doi.org/10.1176/ajp.149.9.1244 
[54] Rettew, D.C., Swedo, S.E., Leonard, H.L., et al. (1992) Obsessions and Compulsions across Time in 79 Children and Adolescents with Obsessive Compulsive Disorder. Journal of the American Academy of Child and Adolescent Psychiatry, 31, 1050-1056. http://dx.doi.org/10.1097/00004583-199211000-00009

[55] Swedo, S.E., Leonard, H.L., Garvey, M., et al. (1998) Pediatric Autoimmune Neuropsychiatric Disorders Associated with Streptococcal Infections: Clinical Description of the First 50 Cases. American Journal of Psychiatry, 155, 264-271.

[56] Zabriskie, J.B., Lavenchy, D., Williams Jr., R.C., et al. (1985) Rheumatic Fever Associated with B Cell Alloantigens as Identified by Monoclonal Antibodies. Arthritis \& Rheumatology, 28, 1047-1051. http://dx.doi.org/10.1002/art.1780280912

[57] Mabrouk, A.A. and Ezpen, V. (2008) Challenges in the Identification and Treatment of PANDAS: A Case Series. Journal of Tropical Pediatrics, 55, 46-48. http://dx.doi.org/10.1093/tropej/fmn039

[58] Kirvan, C.A., Swedo, S.E., Kurahara, D., et al. (2006) Streptococcal Mimicry and Antibody-Mediated Cell Signaling in the Pathogenesis of Sydenham's Chorea. Autoimmunity, 39, 21-29. http://dx.doi.org/10.1080/08916930500484757

[59] Froude, .J, Gibofsky, A., Buskirk, D.R., et al. (1989) Cross-Reactivity between Streptococcus and Human Tissue: A Model of Molecular Mimicry and Autoimmunity. Current Topics in Microbiology and Immunology, 145, 5-26. http://dx.doi.org/10.1007/978-3-642-74594-2_2

[60] Dudding, B.A. and Ayoub, E.M. (1968) Persistence of Streptococcal Group a Antibody in Patients with Rheumatic Valvular Disease. Journal of Experimental Medicine, 128, 1081 1098. http://dx.doi.org/10.1084/jem.128.5.1081

[61] Quattrini, A., Lorenzetti, I., Sciorati, C., et al. (2001) Human IgM and anti-GM1 Autoantibodies Modulate Intracellular Calcium Hemeostasis in Neuroblastoma Cells. Journal of Neuroimmunology, 114, 213-319. http://dx.doi.org/10.1016/S0165-5728(00)00452-5

[62] Kasahara, K., Watanabe, K., Takeuchi, K., et al. (2000) Involvement of Gangliosides in Glycosylphosphatidylinositol-Anchored Neuronal Cell Adhesion Molecule TAG-1 Signaling in Lipid Rafts. Journal of Biological Chemistry, 275, 34701-34709. http://dx.doi.org/10.1074/jbc.M003163200

[63] Perlmutter, S.J., Leitman, S.F., Garvey, M.A., et al. (1999) Therapeutic Plasma Exchange and Intravenous Immunoglobulin for Obsessive-Compulsive Disorder and Tic Disorders in Childhood. Lancet, 354, 1153-1158. http://dx.doi.org/10.1016/S0140-6736(98)12297-3

[64] Hersh, A.L.B., Geng, A., Cushing-Ruby, H., et al. (2006) Resolution of PANDAS Like Symptoms by IVIg in a Patient with Specific Antibody Deficiency against Polysaccharide Antigens. Journal of Allergy and Clinical Immunology, 117, S519. http://dx.doi.org/10.1016/j.jaci.2005.12.077

[65] Hachiya, Y., Miyata, R., Tanuma, N., et al. (2013) Autoimmune Neurological Disorders Associated with Group-A Beta-Hemolytic Streptococcal Infection. Brain \& Development, 35, 670-674. http://dx.doi.org/10.1016/j.braindev.2012.10.003

[66] Frankovich, J., Thienemann, M., Rana, S., et al. (2015) Five Youth with Pediatric AcuteOnset Neuropsychiatric Syndrome of Differing Etiologies. Journal of Child and Adolescent Psychopharmacology, 25, 31-37. http://dx.doi.org/10.1089/cap.2014.0056

[67] Kovacevic, M., Grant, P. and Swedo, S.E. (2015) Use of Intravenous Immunoglobulin in the Treatment of Twelve Youths with Pediatric Autoimmune Neuropsychiatric Disorders Associated with Streptococcal Infections. Journal of Child and Adolescent Psychopharmacology, 25, 65-69. http://dx.doi.org/10.1089/cap.2014.0067

[68] Bouboulis, D.A. and Mast, P.A. (2016) Infection-Induced Autoimmune Encephalopathy: 
Treatment with Intravenous Immune Globulin Therapy. A Report of Six Patients. International Journal of Neurology Research, 2, 256-258.

http://dx.doi.org/10.17554/j.issn.2313-5611.2016.02.44

[69] Younger, D.S., Mast, P.A. and Bouboulis, D.A. (2016) PANDAS: Baseline Immunoglobulin Levels Predict Achievement of Remission at One Year Following IVIg Therapy. Journal of Neurology and Neurosurgery, 3, 122. http://dx.doi.org/10.19104/jnn.2016.22

[70] Bailey, A., Phillips, W. and Rutter, M. (1996) Autism: Towards an Integration of Clinical, Genetic, Neuropsychological, and Neurobiological Perspectives. Journal of Child Psychology and Psychiatry, 37, 89-126. http://dx.doi.org/10.1111/j.1469-7610.1996.tb01381.x

[71] American Psychiatric Association (2013) Diagnostic and Statistical Manual of Mental Disorders. 5th Edition, American Psychiatric Association, Arlington. Gillgerg, C. and Wing, L. (1999) Autism: Not an Extremely Rare Disorder. Acta Psychiatrica Scandinavica, 99, 399406.

[72] Blumberg, S.J., Bramlett, M.D., Kogan, M.D., et al. (2013) Changes in Prevalence of Parent-Reported Autism Spectrum Disorder in School-Age US Children: 2007 to 2011-2012. National Health Statistics Reports, 65, 1-11.

[73] Baio, J. (2014) Prevalence of Autism Spectrum Disorder among Children Aged 8 YearsAutism and Developmental Disabilities Monitoring Network, 11 Sites, United States, 2010. Surveillance Summaries, 63, 1-21

[74] Wazana, A., Bresnahan, M. and Kline, J. (2007) The Autism Epidemic: Factor or Artifact? Journal of the American Academy of Child \& Adolescent Psychiatry, 46, 721-730. http://dx.doi.org/10.1097/chi.0b013e31804a7f3b

[75] Baxter, A.J., Brugha, T.S., Erskine, H.E., et al. (2015) The Epidemiology and Global Burden of Autism Spectrum Disorders. Psychological Medicine, 45, 601-613. http://dx.doi.org/10.1017/S003329171400172X

[76] Wakefield, A.J., Murch, S.H., Anthony, A., et al. (1998) Ileal-Lymphoid-Nodular Hyperplasia, Non-Specific Colitis, and Pervasive Developmental Disorder in Children. Lancet, 351, 637-641. http://dx.doi.org/10.1016/S0140-6736(97)11096-0

[77] Wakefield, A.J., Anthony, A., Schepelmann, S., et al. (1998) Persistent Measles Virus Infection and Immunodeficiency in Children with Autism, Ileo-Colonic Lymphoid Nodular Hyperplasia and Non-Specific Colitis. Gut, 42, A86.

[78] Wakefield, A.J. and Montgomery, S.M. (1999) Autism, Viral Infection and MeaslesMumps-Rubella Vaccination. Israel Medical Association Journal, 1, 183-187.

[79] Hooker, B.S. (2014) Measles-Mumps-Rubella Vaccination Timing and Autism among Young African American Boys: A Reanalysis of CDC Data. Translational Neurodegeneration, 3, 16. http://dx.doi.org/10.1186/2047-9158-3-16

[80] DeStefano, F., Bhasin, T.K., Thompson, W.W., et al. (2004) Age at First Measles-MumpsRubella Vaccination in Children with Autism and School-Matched Control Subjects: A Population-Based Study in Metropolitan Atlanta. Pediatrics, 113, 259-266. http://dx.doi.org/10.1542/peds.113.2.259

[81] Hooker, B.S. (2014) Retraction: Measles-Mumps-Rubella Vaccination Timing and Autism among Young African American Boys: A Reanalysis of CDC Data. Translational Neurodegeneration, 3, 22. http://dx.doi.org/10.1186/2047-9158-3-22

[82] Madsen, K.M., Hviid, A., Vestergaard, M., et al. (2002) A Population-Based Study of Measles, Mumps, and Rubella Vaccination and Autism. New England Journal of Medicine, 347, 1477-1482. http://dx.doi.org/10.1056/NEJMoa021134

[83] Taylor, L.E., Swerdfeger, A.L., Eslick, G.D., et al. (2014) Vaccines Are Not Associated with 
Autism: An Evidence-Based Meta-Analyses of Case-Control and Cohort Studies. Vaccine, 32, 3623-3629. http://dx.doi.org/10.1016/j.vaccine.2014.04.085

[84] Hornig, M., Briese, T., Buie, T., et al. (2008) Lack of Association between Measles Virus Vaccine and Autism with Enteropathy: A Case Control Study. PLoS ONE, 3, e3140. http://dx.doi.org/10.1371/journal.pone.0003140

[85] Bresnanhan, M., Hornig, M., Schultz, A.F., et al. (2015) Association of Maternal Report of Infant and Toddler Gastrointestinal Symptoms with Autism: Evidence from a Prospective Birth Cohort. JAMA Psychiatry, 72, 466-474. http://dx.doi.org/10.1001/jamapsychiatry.2014.3034

[86] deMagistris, L., Familiari, V., Pascotto, A., et al. (2010) Alterations of the Intestinal Barrier in Patients with Autism Spectrum Disorders and in Their Fist-Degree Relatives. Journal of Pediatric Gastroenterology and Nutrition, 51, 418-424. http://dx.doi.org/10.1097/MPG.0b013e3181dcc4a5

[87] Patterson, P.H. (2011) Maternal Infection and immune involvement In Autism. Trends in Molecular Medicine, 17, 389-394. http://dx.doi.org/10.1016/j.molmed.2011.03.001

[88] Patterson, P.H. (2009) Immune Involvement in Schizophrenia and Autism: Etiology, Pathology and Animal Models. Behavioural Brain Research, 204, 313-321. http://dx.doi.org/10.1016/j.bbr.2008.12.016

[89] Singer, H.S., Morris, C., Gause, C., et al. (2009) Prenatal Exposure of Antibodies from Mothers of Children with Autism Produces Neurobehavioral Alterations: A Pregnant Dam Mouse Model. Journal of Neuroimmunology, 211, 39-48. http://dx.doi.org/10.1016/j.jneuroim.2009.03.011

[90] Sandin, S., Hultman, C.M., Kolevzon, A., et al. (2012) Advancing Maternal Age Is Associated with Increasing Risk for Autism: A Review and Meta-Analysis. Journal of the American Academy of Child \& Adolescent Psychiatry, 51, 477-486. http://dx.doi.org/10.1016/j.jaac.2012.02.018

[91] Maimburg, R.D. and Vaeth, M. (2006) Perinatal Risk Factors and Infantile Autism. Acta Psychiatrica Scandinavica, 114, 257-264. http://dx.doi.org/10.1111/j.1600-0447.2006.00805.x

[92] Grether, J.K., Anderson, M.C., Croen, L.A., et al. (2009) Risk of Autism and Increasing Maternal and Paternal Age in a Large North American Population. American Journal of Epidemiology, 170, 1118-1126. http://dx.doi.org/10.1093/aje/kwp247

[93] Croen, L., Najjar, D.V., Fireman, B., et al. (2007) Maternal and Paternal Age and Risk of Autism Spectrum Disorders. Archives of Pediatrics \& Adolescent Medicine, 161, 334-340. http://dx.doi.org/10.1001/archpedi.161.4.334

[94] Durkin, M.S., Maenner, M.J., Newschaffer, C.J., et al. (2008) Advanced Paternal Age and the Risk of Autism Spectrum Disorder. American Journal of Epidemiology, 168, 1268-1276. http://dx.doi.org/10.1093/aje/kwn250

[95] Glasson, E.J., Bower, C., Petterson, B., et al. (2004) Perinatal Factors and the Development of Autism. A Population Study. Archives of General Psychiatry, 61, 618-627. http://dx.doi.org/10.1001/archpsyc.61.6.618

[96] Ornoy, A., Weinstein-Fudim, L. and Ergaz, Z. (2015) Prenatal Factors Associated with Autism Spectrum Disorder (ASD). Reproductive Toxicology, 56, 155-169. http://dx.doi.org/10.1016/j.reprotox.2015.05.007

[97] Stoltenberg, C., Schjolberg, S., Bresnahan, M., et al. (2010) The Autism Birth Cohort (ABC): A Paradigm for Gene-Environment-Timing Research. Molecular Psychiatry, 15, 676-680. http://dx.doi.org/10.1038/mp.2009.143 
[98] Benayed, R., Gharani, N., Rossman, I., et al. (2005) Support for the Homeobox Transcription Factor Gene ENGRAILED 2 as an Autism Spectrum Disorder Susceptibility Locus. American Journal of Human Genetics, 77, 851-868. http://dx.doi.org/10.1086/497705

[99] Online Mendelian Inheritance in Man (OMIM ${ }^{\oplus}$ ) (2016) McKusick-Nathans Institute of Genetic Medicine. Johns Hopkins University, Baltimore. http://omim.org

[100] Chez, M.G. and Guido-Estrada, N. (2010) Immune Therapy in Autism: Historical Experience and Future Directions with Immunomodulatory Therapy. Neurotherapeutics, 7, 293- 301. http://dx.doi.org/10.1016/j.nurt.2010.05.008

[101] Younger, D.S. (2016) PANDAS plus Autism: Treatment with IVIg. International Journal of Neurology Research, 2, 224-225. http://dx.doi.org/10.17554/j.issn.2313-5611.2016.02.43

\section{Submit or recommend next manuscript to SCIRP and we will provide best service} for you:

Accepting pre-submission inquiries through Email, Facebook, LinkedIn, Twitter, etc. A wide selection of journals (inclusive of 9 subjects, more than 200 journals)

Providing 24-hour high-quality service

User-friendly online submission system

Fair and swift peer-review system

Efficient typesetting and proofreading procedure

Display of the result of downloads and visits, as well as the number of cited articles

Maximum dissemination of your research work

Submit your manuscript at: http://papersubmission.scirp.org/

Or contactwjns@scirp.org 